\title{
MICROSTRUCTURE OF GaN GROWN ON (111) Si BY MOCVD
}

\author{
D. M. Follstaedt, J. Han, P. Provencio and J. G. Fleming
}

Sandia National Laboratories, Albuquerque, NM 87185-1056

Cite this article as: MRS Internet J. Nitride Semicond. Res. 4S1, G3.72 (1999)

\section{ABSTRACT}

Gallium nitride was grown on (111) Si by MOCVD by depositing an AlN buffer at $1080^{\circ} \mathrm{C}$ followed by $\mathrm{GaN}$ at $1060^{\circ} \mathrm{C}$. The $2.2 \mu \mathrm{m}$ layer cracked along $\{1-100\}$ planes upon cooling to room temperature, but remained adherent. We were nonetheless able to examine the material between cracks with TEM. The character and arrangement of dislocations are much like those of $\mathrm{GaN}$ grown on $\mathrm{Al}_{2} \mathrm{O}_{3}$ : 2/3 pure edge and $\sim 1 / 3$ mixed (edge + screw), arranged in boundaries around domains of $\mathrm{GaN}$ that are slightly misoriented with respect to neighboring material. The $30 \mathrm{~nm}$ AlN buffer is continuous, indicating that $\mathrm{AlN}$ wets the $\mathrm{Si}$, in contrast to $\mathrm{GaN}$ on $\mathrm{Al}_{2} \mathrm{O}_{3}$.

\section{INTRODUCTION}

Hexagonal GaN is being widely studied because of its large, direct bandgap and high thermal stability. Applications are envisioned in technologies involving short wavelength (green, blue and UV) optoelectronics and high-temperature or high-power electronics. A key issue for growth of $\mathrm{GaN}$ has been the lack of an ideal substrate, since GaN substrates are not readily available and other semiconductors have large lattice mismatches. Most GaN has been grown on sapphire $\left(\mathrm{Al}_{2} \mathrm{O}_{3}\right)$; vapor-phase growth usually begins with deposition of a low temperature $\mathrm{GaN}$ buffer followed by the complete layer at near $1000^{\circ} \mathrm{C}$. Applications with sapphire are limited by its lack of electrical conductivity and high cost.

We have investigated growth of $\mathrm{GaN}$ on $\mathrm{Si}$ with the intent of integrating short-wavelength devices into Si-based microelectronics, as well as providing an alternative substrate. We have grown GaN by metal-organic chemical vapor deposition (MOCVD) on (111) Si and obtained microstructures much like those for sapphire, but cracking during cooling to room temperature limits use of our current materials. Here we use transmission electron microscopy (TEM) to examine dislocations in the GaN and the structure of the AlN buffer layer grown at the interface with the $\mathrm{Si}$, and compare them to corresponding microstructures of $\mathrm{GaN}$ grown on $\mathrm{Al}_{2} \mathrm{O}_{3}$. An introduction to this work and our related approaches to growth on $\mathrm{Si}$ is given elsewhere [1].

\section{GROWTH OF GaN}

A 1000 rpm rotating disk reactor with 4.75" quartz chamber was used to grow AlN and $\mathrm{GaN}$ with trimethylgallium, trimethylaluminum, and ammonia precursors at 30 Torr [1]. Several investigations indicate that growing an AIN buffer first on Si avoids the formation of amorphous $\mathrm{Si}_{3} \mathrm{~N}_{4}$ since $\mathrm{N}$ reacts more exothermically with $\mathrm{Al}$ than $\mathrm{Si}$; this is important for attaining good epitaxial growth of $\mathrm{GaN}[2,3]$. Our methods follow those of Watanabe et al [2] who found that AlN buffer growth at $>1000^{\circ} \mathrm{C}$ leads to good epitaxy, in spite of the $17 \%$ lattice mismatch of $\mathrm{GaN}$ with Si. We grew a $30 \mathrm{~nm} \mathrm{AlN}$ buffer at $1080^{\circ} \mathrm{C}$, followed by $2.2 \mu \mathrm{m}$ of $\mathrm{GaN}$ at $1060^{\circ} \mathrm{C}$.

In situ reflectivity indicated that the GaN surface was smooth immediately after growth at $1060^{\circ} \mathrm{C}$. However, upon cooling to room temperature, a dense set of cracks with separations 


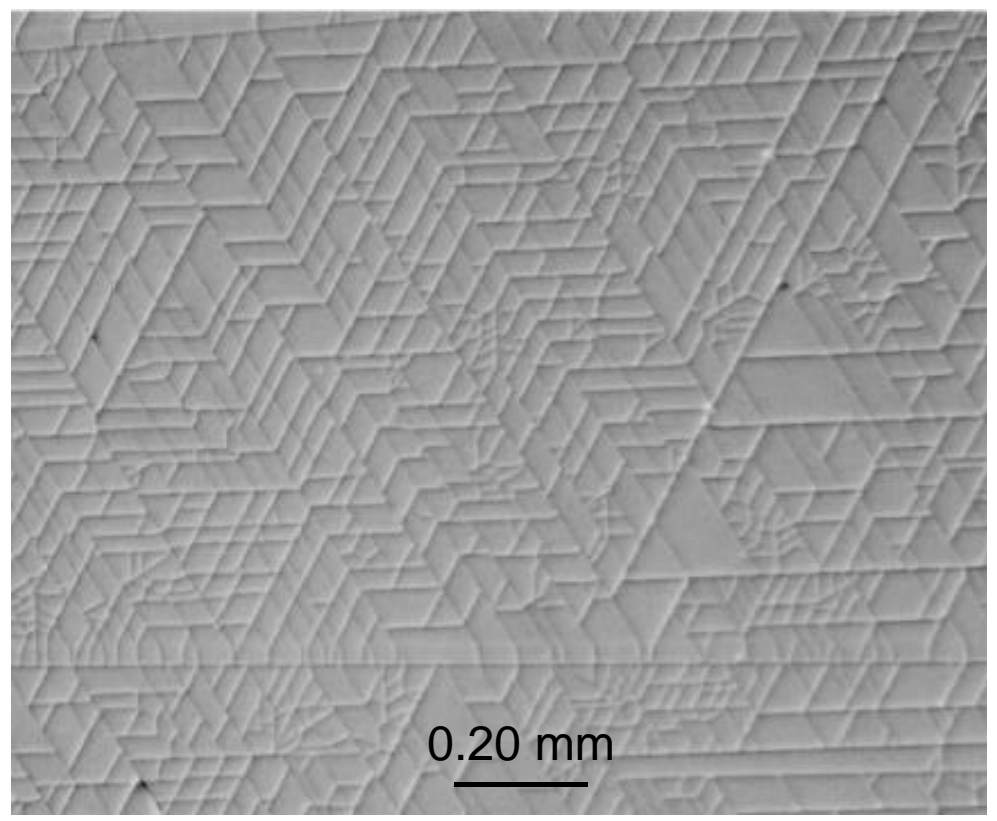

Figure 1. Nomarski optical micrograph showing cracking of $\mathrm{GaN}$ on (111) Si along $\{1-100\}$ planes. from 20 to $100 \mu \mathrm{m}$ was found along $\{1-100\}$ planes, as seen in Figure 1. The layer is expected to have relaxed fully at the growth temperature, as found for $\mathrm{GaN}$ grown on $\mathrm{Al}_{2} \mathrm{O}_{3}$ using in situ stress monitoring techniques [4]. The greater thermal expansion coefficient of $\mathrm{GaN}$ as compared to that of $\mathrm{Si} \quad\left(5.6 \times 10^{-6} / \mathrm{K} \quad \mathrm{vs}\right.$. $2.6 \times 10^{-6} / \mathrm{K}$, respectively) then explains cracking since the $\mathrm{GaN}$ layer would be put into tension upon cooling. In spite of cracking, the GaN layer adhered to the substrate. X-ray diffraction of such layers gives (0002) GaN reflections with FWHM of 900 arcsec, similar to those found previously [2].

\section{TEM CHARACTERIZATION OF DEFECTS IN GaN}

Cross-section TEM specimens were successfully prepared by usual metallographic polishing and ion milling methods for both [110] and [1-12] Si orientations in spite of the cracking. Cracks were found passing directly across the layer and into the Si substrate. The cracks were open with no indication of subsequent deposition, consistent with their forming after growth [1]. No evidence of de-adhesion of the layer from the substrate was seen where the cracks cross the interface into the Si. The GaN layer was found to be single phase and with no $30^{\circ}$-misoriented grains as seen in other material grown by molecular beam epitaxy (MBE) [5]. Selected-area diffraction demonstrated the epitaxial orientation seen previously for $\mathrm{GaN}$ on (111) $\mathrm{Si}[2,3,5]$ :

$\begin{array}{cc}(0001) \|(111) & \text { interface plane } \\ {[1-100] \|[11-2]} & \text { direction in plane } \\ {[11-20] \|[1-10]} & \text { “ }\end{array}$

Dislocations thread from the buffer layer to the surface of the GaN layer along the c-axis, growth direction. Examination in cross-section with different diffracting beams can be used to determine the Burger's vectors of individual dislocations, which for hexagonal close-packed lattices are [6]: a (or 1/3 $\langle 11-20\rangle$, in the basal lattice plane), $\mathbf{c}(\langle 0001\rangle$, along the hexagonal axis), or $\mathbf{a}+\mathbf{c}(1 / 3<11-23\rangle$, mixed character). In Figure 2, image (a) uses the (0004) reflection to illuminate the cores of dislocations with Burger's vectors having a c-axis component. Image (b) uses (1-100) to image those with a basal plane component. Detailed examinations with several reflections indicate that almost all dislocations are detected in Figure 2b) and have a basal-plane component. Those with a c-axis component seen in Fig. $2 \mathrm{a}(\sim 1 / 3$ of the total) are almost all of mixed character. The additional ones in Fig. $2 b(\sim 2 / 3$ of the total) have purely basal-plane Burger's vectors, $\mathbf{b}=\mathbf{a}$; since the dislocation lines are fairly straight along the c-axis, these are edge dislocations. Very few dislocations have $\mathbf{b}=\mathbf{c}$ corresponding to pure screw character. This distribution of Burger's vectors is like that found by us [7] and others [8] in GaN on sapphire. 

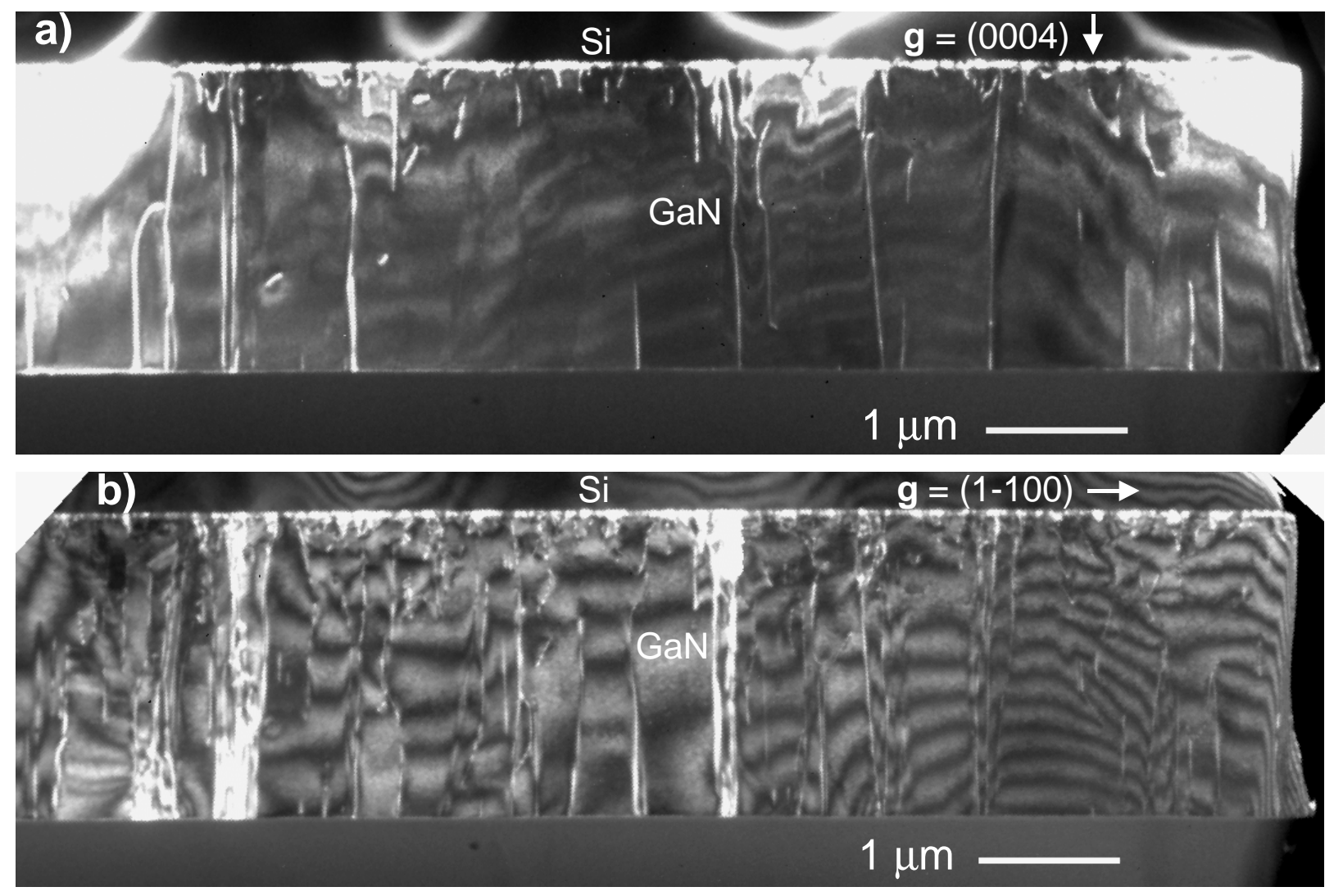

Figure 2. Weak-beam TEM images obtained near [11-20] orientation. a) $\mathbf{g}=(0004)$, with cores of dislocations having $\mathbf{b}=\mathbf{a}+\mathbf{c}$ illuminated. b) $g=(1-100)$, with cores of all dislocations illuminated. A crack running through the layer and into the Si substrate is seen at far right.

Plan-view TEM gives additional insight into the dislocation arrangement. A specimen was prepared by placing thinned epoxy on the specimen surface to penetrate into cracks, removing excess epoxy from the surface, and carefully backthinning with the specimen attached to a grid for structural support. The thinned area is at the surface of the GaN layer and allows defects threading to it to be detected. In Figure 3, the dislocations are viewed nearly end-on and appear as short black-white segments. They often lie along continuous curves that form boundaries between domains of material with slightly differing orientations. A similar arrangement is found for threading dislocations in GaN grown on sapphire [9]. Plan-view images allow more surface area to be examined than in cross-section and give the most accurate determination of dislocation density at the surface: $8 \times 10^{9} \mathrm{dis} 1 / \mathrm{cm}^{2}$ for this specimen. This density is like that found for GaN grown on sapphire [7], although lower values have been achieved [8].

By examining this greater surface area, an additional defect with a low density is found. Two void-like defects were identified in Figure 3 (small white spots, arrowed) by examining their contrast with changes in TEM objective lens focus. Such defects have been termed "nanotubes" if they have extended length into the GaN, or "pinholes" if they are pits located at surface [10]. Since we do not have depth information, we cannot determine which of the two classifications apply. Other images taken under high resolution conditions show that the $\{1-100\}$ lattice planes form facets around the voids. Their areal density is $\sim 1 \times 10^{8} / \mathrm{cm}^{2}$, again comparable to that found in $\mathrm{GaN}$ grown on sapphire [10]. 


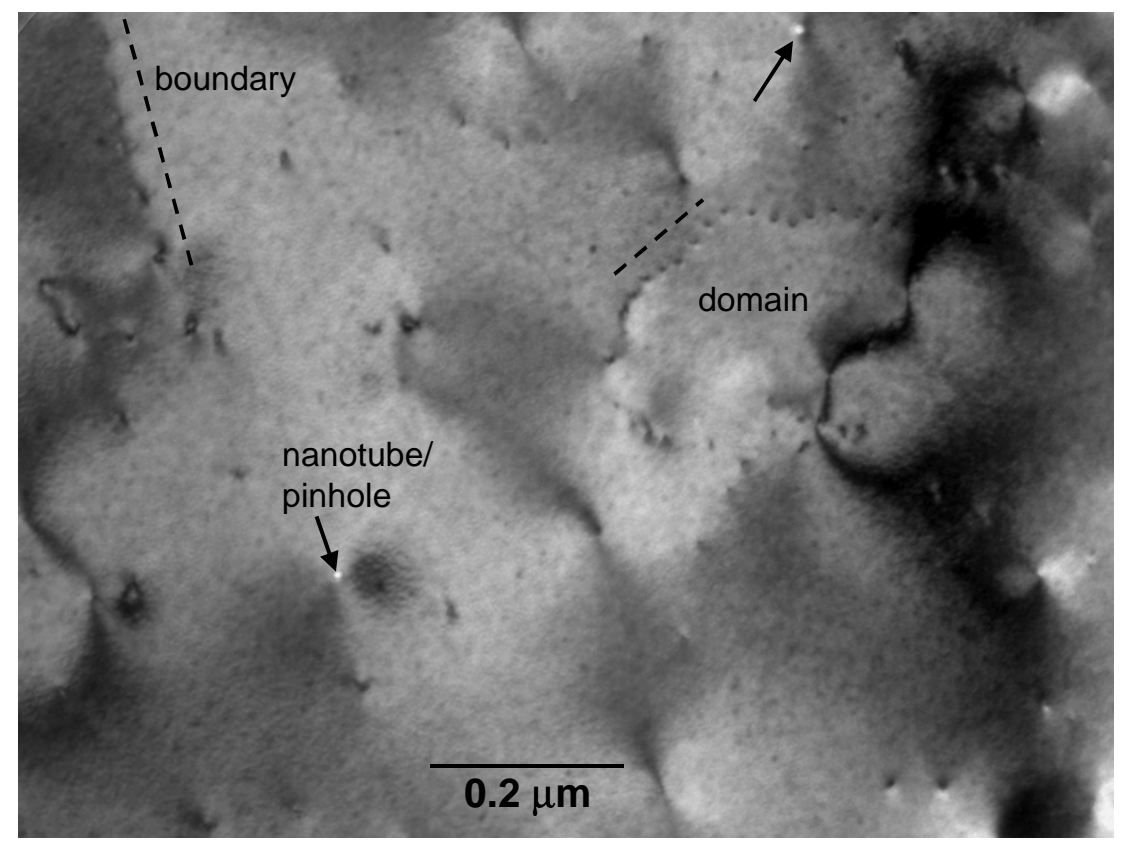

Figure 3. Plan-view TEM image of the surface of the $\mathrm{GaN}$ layer, obtained near [0001] orientation using $\mathrm{g}=$ (1-100) two-beam conditions in bright-field. Dislocations appear as short black-white lines, and often form continuous curves at boundaries between domains of material with slightly differing orientations; two are noted with nearby dashed lines. Two voidlike defects (nanotubes or pinholes) are also noted with arrows.

\section{EXAMINATION OF AIN BUFFER LAYERS}

The buffer layer was found to be continuous over extended distances in cross-section images. It's thickness varies somewhat as seen in Figure 4a, but it is readily identified from the $\mathrm{GaN}$ overlayer. By tilting the specimen slightly to vary the contrast in bright field, or by weakbeam examinations like Figure $4 \mathrm{~b}$, the layer is seen to be composed of grains that are 20-40 nm across and slightly misoriented with respect to each other.

Dislocations in the GaN just above the buffer interact with each other, as seen in Figure 4. The dislocations extend into the AlN buffer at near-normal incidence. In some cases, they appear to coincide with grain boundaries in the buffer; two instances are arrowed in Figure 4b. This suggests that the misorientations between AlN buffer grains may directly produce some of the dislocations threading through the GaN. Perhaps if a buffer layer with larger grains were formed, the GaN would have fewer defects.
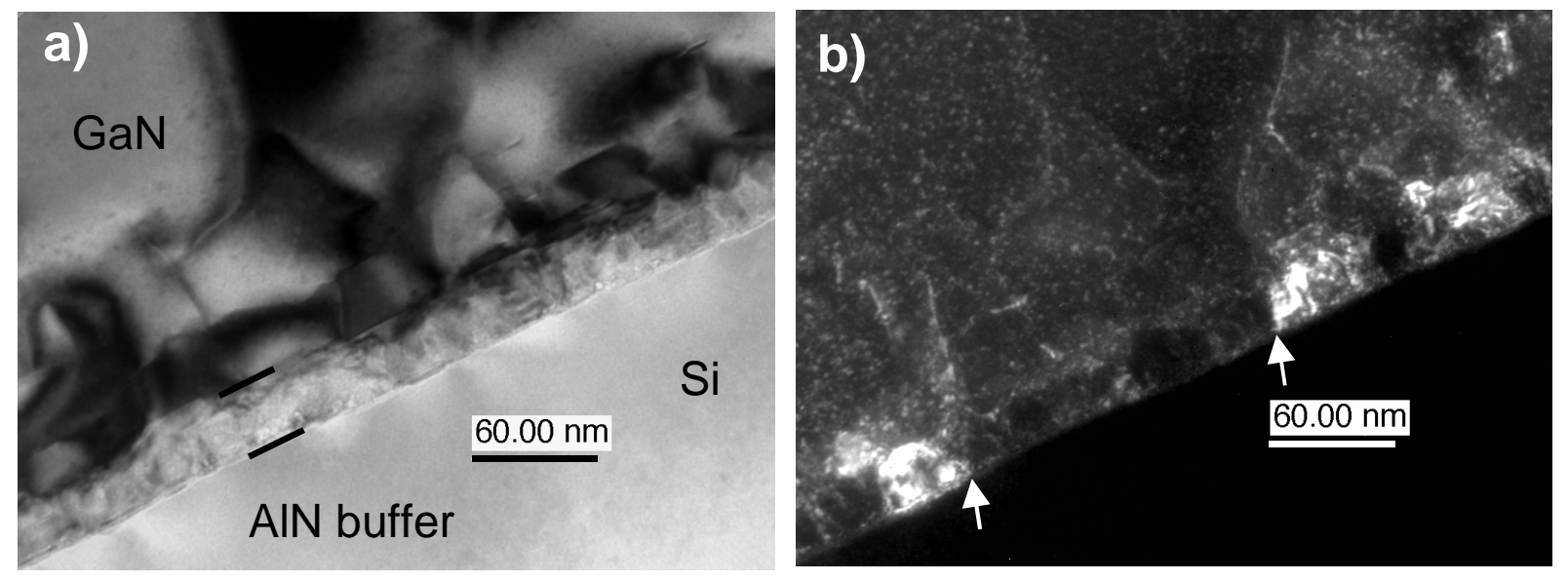

Figure 4. a) Bright-field, (3-300) two-beam image of AlN buffer on Si near [11-20] cross-section orientation with dislocations extending into GaN layer. b) Corresponding weak-beam image showing 20-40 nm grains in the buffer with contrast between them indicating slight orientation differences. Two dislocations appear to originate at grain boundaries in the buffer (arrowed). 


\section{AIN}

void

Si

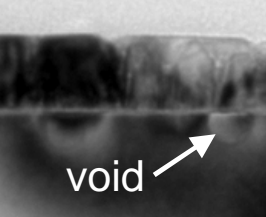

(1)

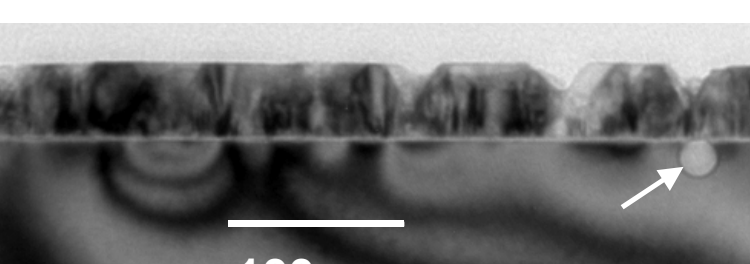

$100 \mathrm{~nm}$

Figure 5. Cross-section TEM image of $40 \mathrm{~nm}$ AlN buffer grown on (111) Si, seen in [11-20] orientation with $g=(0002)$ two-beam conditions. Grains in the AlN buffer are faceted at the top surface, and two voids (arrowed) can be seen just below the interface in the Si.

Having a continuous $30 \mathrm{~nm}$-thick AlN layer on Si implies that the AlN "wets" the Si under our conditions, indicating that the AlN/Si interface has lower energy than the AlN/vacuum surface. A continuous AlN layer was also found for an even thinner $(8 \mathrm{~nm})$ buffer grown on $\mathrm{Si}$ by MBE [3]. Such continuous layers differ greatly from those observed for GaN grown by MOCVD on $\mathrm{Al}_{2} \mathrm{O}_{3}$ using a low-temperature buffer layer followed by high-temperature growth. For $\mathrm{GaN} / \mathrm{Al}_{2} \mathrm{O}_{3}$ the layer must be $0.4 \mu \mathrm{m}$ thick before it is continuous [10]. The wetting may indicate that more favorable bonding is occuring between nitrides and the Si. Such good bonding is suggested by the adhesion of the layer to the substrate as evidenced by the cracks propagating across the interface instead of along it. Thus Si appears to be the preferred substrate for initiating growth of nitrides when used with an AlN buffer.

A cross-section TEM specimen was also made of a $40 \mathrm{~nm}$-thick AlN buffer layer grown alone on (111) Si at $1100^{\circ} \mathrm{C}$. The layer was again found to be continuous with slight misorientations between grains, as seen in Figure 5. Our examinations indicated two other features of this layer. First the individual grains composing the buffer exhibit faceting on the growth surface; the facets appear to be $\{1-101\}$ lattice planes. Secondly, a few voids were found in the $\mathrm{Si}$ immediately beneath the interface, which suggests that Si may be diffusing into the AlN.

\section{DISCUSSION}

Microstructural features of $\mathrm{GaN}$ grown on $\mathrm{Si}$ are compared with those for growth on sapphire in Table I. Cracking clearly remains a problem for the Si substrate that must be overcome before devices can be made. The microstructures of threading dislocations are very similar in GaN grown on the two substrates; in both cases the threading dislocations appear due to small local misorientations between adjacent materials. It may be possible to influence the dislocation density with Si by varying the growth conditions of the AlN buffer.

The buffer layers are very different, with $\mathrm{AlN}$ wetting $\mathrm{Si}$ but $\mathrm{GaN}$ not wetting $\mathrm{Al}_{2} \mathrm{O}_{3}$ even after subsequent high-temperature growth. This difference this may reflect a change in bonding across the interface, although differing deposition temperatures and differences between AlN and $\mathrm{GaN}$ need to be considered. Since $\mathrm{Si}$ is covalent whereas $\mathrm{Al}_{2} \mathrm{O}_{3}$ is ionic, the change may be due to covalent bonding of the AlN to the Si. The faulting seen [8] in nucleation layers for $\mathrm{GaN}$ on $\mathrm{Al}_{2} \mathrm{O}_{3}$ is associated with the low-temperatures needed to induce growth of $\mathrm{GaN}$, which then occurs in both its fcc and hcp phases; we have not detected faulting in our high-temperature AlN buffer layers. 
Table I. Comparison of Microstructures: $\mathrm{GaN} / \mathrm{Al}_{2} \mathrm{O}_{3}$ versus $\mathrm{GaN} / \mathrm{Si}$

Cracking:

Dislocations:

density

character

arrangement

nanotubes, pinholes

Buffer: $\quad$ type (temperature)

wetting

thickness for continuity

microstructure
$\underline{\mathrm{GaN} / \mathrm{Al}_{2}} \underline{\mathrm{O}}_{3}$

no

$10^{8}-10^{10} / \mathrm{cm}^{2}[7-9]$

$1 / 3$ mixed, $2 / 3$ edge [8]

boundaries [9]

$10^{6}-10^{8} / \mathrm{cm}^{2}$ [10]

$\mathrm{GaN}\left(550^{\circ} \mathrm{C}\right)$ [7]

no

$\sim 0.4 \mu \mathrm{m}$ [11]

faulted (hcp/fcc) [8]
GaN/Si (this work)

yes, $\{1-100\}$ planes

$8 \times 10^{9} / \mathrm{cm}^{2}$

$1 / 3$ mixed, $2 / 3$ edge

domain walls

$\sim 10^{8} / \mathrm{cm}^{2}$

$\operatorname{AlN}\left(1080^{\circ} \mathrm{C}\right)$

yes

$\sim 30 \mathrm{~nm}$

hcp grains $(20-40 \mathrm{~nm})$

\section{ACKNOWLEDGEMENTS}

The authors would like to thank S. Hearne and J. Floro for discussions about stress in GaN layers during growth, and S. R. Lee for discussions about cracking in GaN layers on Si. This work at Sandia National Laboratories supported by the United States Department of Energy under Contract DE-AC04-94A185000. Sandia is a multiprogram laboratory operated by Sandia Corporation, a Lockheed Martin Company for the United States Department of Energy.

\section{REFERENCES}

1. J. Han, J. G. Flemming and D. M. Follstaedt, Mat. Res. Soc. Symp. Proc. 512, 53 (1998).

2. A. Watanabe, T. Takuchi, K. Hirosawa, H. Amano, K. Hiramatsu and I. Akasaki, J. Crystal Growth, 128, 391-396 (1993).

3. S. Guha and N. A. Bojarczuk, Appl. Phys. Lett. 72, 415 (1998).

4. S. Hearne, J. A. Floro and I. Tsong, private communication (in situ stress measurements).

5. S. N. Basu, T. Lei and T. D. Moustakas, J. Mater. Res. 9, 2370 (1994).

6. J. P. Hirth and J. Lothe, Theory of Dislocations, $2^{\text {nd }}$ ed. (Krieger Publishing Co., Malabar, FL, 1992) p. 270.

7. Dislocations were analyzed as described herein; the growth of our $\mathrm{GaN}$ on sapphire is discussed by T.-B. Ng, J. Han, R. M. Biefeld and M. V. Weckwerth, J. Electron. Mat. 27, 190 (1998).

8. X. H. Wu, L. M. Brown, D. Kapolnek, S. Keller, B. Keller, S. P. DenBaars and J. S. Speck, J. Appl. Phys. $\underline{80}, 3228$ (1996).

9. X. J. Ning, F. R. Chien, P. Pirouz, J. W. Yang and M. A. Khan, J. Mater. Res. 11, 580 (1996).

10. Z. Liliental-Weber, Y. Chen, S. Ruvimov and J. Washburn, Phys. Rev. Lett. 79, 2835 (1997).

11. X.H. Wu, P. Fini, S. Keller, E.J. Tarsa, B. Heying, U.K Mishra, S.P. DenBaars and J.S. Speck, Jpn. J. Appl. Phys. Pt.2, 35 L1648 (1996). 